SCHMIDT, Felipe. Ministério Público, Poder Judiciário e Representação Funcional e Argumentativa: Fundamentos de Legitimidade para a atuação institucional. Revista Eletrônica Direito e Política, Programa de Pós-Graduação Stricto Sensu em Ciência Jurídica da UNIVALI, Itajaí, v.13, n.2, $2^{\circ}$ quadrimestre de 2018. Disponível em: www.univali.br/direitoepolitica - ISSN 1980-7791

\title{
MINISTÉRIO PÚBLICO, PODER JUDICIÁRIO E REPRESENTAÇÃO FUNCIONAL E ARGUMENTATIVA: FUNDAMENTOS DE LEGITIMIDADE PARA A ATUAÇÃO INSTITUCIONAL
}

\author{
PUBLIC MINISTRY, JUDICIARY POWER AND FUNCTIONAL AND ARGUMENTATIVE
}

REPRESENTATION: LEGITIMACY FOUNDATIONS FOR INSTITUTIONAL ACTION

\section{Felipe Schmidt ${ }^{1}$}

SUMÁRIO: Introdução; 1 A Crise do Sistema Democrático-Representativo no Brasil; 2 A Representação Funcional; 3 A Representação Argumentativa; Considerações Finais; Referência das Fontes Citadas.

\section{RESUMO}

O presente estudo examina a representação funcional e a representação argumentativa como fundamentos de legitimidade para a atuação institucional do Ministério Público e do Poder Judiciário. Conclui que tais formas de representação não substituem ou superam a representação tradicional dos agentes políticos eleitos pelo povo, mas apenas a complementam, ampliando espaços de cidadania.

Palavras-chave: Poder Judiciário; Ministério Público; representação funcional; representação argumentativa; legitimidade; atuação institucional.

\section{ABSTRACT}

The present study examines functional representation and argumentative representation as grounds of legitimacy for the institutional performance of the Public Prosecution Service and the Judiciary. It concludes that such forms of representation do not replace or surpass the traditional representation of the political agents elected by the people, but only complement it, broadening spaces of citizenship.

Keywords: Judicial Power; Public Ministry; functional representation; argumentative representation; legitimacy; functional performance.

1 Membro do Ministério Público do Estado de Santa Catarina e Mestre em Ciência Jurídica pela Universidade do Vale do Itajaí/SC; Fraiburgo, Santa Catarina, Brasil, e-mail: felipeschmidt@mpsc.mp.br 
SCHMIDT, Felipe. Ministério Público, Poder Judiciário e Representação Funcional e Argumentativa: Fundamentos de Legitimidade para a atuação institucional. Revista Eletrônica Direito e Política, Programa de Pós-Graduação Stricto Sensu em Ciência Jurídica da UNIVALI, Itajaí, v.13, n.2, $2^{\circ}$ quadrimestre de 2018. Disponível em: www.univali.br/direitoepolitica - ISSN 1980-7791

\section{INTRODUÇÃO}

O presente estudo examina a representação funcional e a representação argumentativa como fundamentos de legitimidade para a atuação institucional do Ministério Público e do Poder Judiciário.

Inicialmente, é analisada a crise do sistema democrático-representativo no Brasil, formado pelos Poderes Executivo e Legislativo, cujos integrantes são eleitos pelo voto popular e podem ser controlados pela possibilidade de sua não-reeleição.

Em decorrência dessa crise, a população, que não vê seus anseios espelhados na representação política tradicional, busca outros órgãos, tais quais o Ministério Público e o Poder Judiciário, para dar encaminhamento às suas pretensões.

Assim, surgem a representação funcional e a representação argumentativa, exercidas, entre outros órgãos, pelo Ministério Público e pelo Poder Judiciário, como alternativas à representação tradicional.

O estudo segue com a apreciação dessas duas formas de representação, enfocando suas características, fundamentos jurídicos e políticos, limites e possibilidades, ressaltando que ambas não têm o escopo de suprimir ou minorar a representação política tradicional, mas de complementá-la, ampliando espaços de cidadania.

\section{A CRISE DO SISTEMA DEMOCRÁTICO-REPRESENTATIVO NO BRASIL}

A discussão acerca da representação funcional da sociedade por parte do Poder Judiciário e do Ministério Público deve principiar pelo reconhecimento da crise do sistema democrático-representativo no Brasil.

Em um Estado Democrático, todo poder provém do povo, de modo que, para Robert Alexy, "o exercício de poder estatal pelo parlamento é legítimo porque o parlamento representa o povo. Essa representação é democrática porque os membros do parlamento são eleitos por eleição livre e igual e - por meio da 
SCHMIDT, Felipe. Ministério Público, Poder Judiciário e Representação Funcional e Argumentativa: Fundamentos de Legitimidade para a atuação institucional. Revista Eletrônica Direito e Política, Programa de Pós-Graduação Stricto Sensu em Ciência Jurídica da UNIVALI, Itajaí, v.13, n.2, $2^{\circ}$ quadrimestre de 2018. Disponível em: www.univali.br/direitoepolitica - ISSN 1980-7791

sanção da não reeleição - controlados"2, o mesmo podendo-se dizer da chefia do Poder Executivo.

Ocorre que, segundo Pedro Manoel Abreu, a representação política, à qual caberia a tomada das decisões sobre interesses gerais da coletividade (v.g. economia, educação, saúde), a cargo dos Poderes Executivo e Legislativo, cujos integrantes são democraticamente eleitos pelo voto popular, está em crise ${ }^{3}$.

É que no Brasil as maiorias parlamentares se formam a partir de razões por vezes escusas, movidas por conveniências particulares ou de grupos políticos e econômicos, não raramente em troca de cargos na Administração Pública para acomodar apaniguados políticos e do recebimento de verbas públicas para destinar a bases eleitorais, quando não de pagamentos ilegais por parte de agentes privados interessados na atuação de parlamentares em favor de seus propósitos.

Nessa linha, para Alexandre de Moraes, "o problema central da representação política, portanto, acaba por consistir na impossibilidade de aferir a compatibilidade entre a vontade popular e a vontade expressa pela maioria parlamentar"4.

Outrossim, na lição de José Alcebíades de Oliveira Junior, há

[...] certos preceitos constitucionais que burlam a paridade do sistema de representação política: estados do norte e nordeste com população bem inferior a estados do sul e sudeste com o mesmo número de parlamentares representantes. Ora, isto associado a uma intransparência de certas ações em estados dominados por um coronelismo muito antigo, macula a representação política e portanto a

2 ALEXY, Robert. Constitucionalismo Discursivo, p. 162.

3 ABREU, Pedro Manoel. Processo e Democracia. Florianópolis: Conceito, 2011; p. 277.

${ }^{4}$ MORAES, Alexandre de. Jurisdição Constitucional e Tribunais Constitucionais. Garantia Suprema da Constituição, p. 47. 
SCHMIDT, Felipe. Ministério Público, Poder Judiciário e Representação Funcional e Argumentativa: Fundamentos de Legitimidade para a atuação institucional. Revista Eletrônica Direito e Política, Programa de Pós-Graduação Stricto Sensu em Ciência Jurídica da UNIVALI, Itajaí, v.13, n.2, $2^{\circ}$ quadrimestre de 2018. Disponível em: www.univali.br/direitoepolitica - ISSN 1980-7791

cidadania de milhares de pessoas $(\operatorname{sic})^{5}$.

Quanto ao Poder Executivo, encontrou nas medidas provisórias instrumento de regulação da sociedade, notadamente em matéria econômica, de modo que seu ativismo legislativo impõe nova ordenação da sociedade e do mercado, em ruptura com a tradição constitucional do país ${ }^{6}$, produzindo verdadeira "erosão das formas clássicas de controle parlamentar da produção da lei"7.

Ademais, conforme José Alcebíades de Oliveira Junior, pode-se "constatar um atrelamento inaceitável para a democracia tanto do Poder Legislativo quanto do Poder Judiciário ao Poder Executivo"8. Segundo ele,

[...] um exemplo conhecidíssimo e de infeliz memória foi o bloqueio dos cruzados, que visaria uma distribuição mais justa de bens. E o pior é que o STF, à época, entendeu de não cassar a Medida Provisória 168, transformada em lei 8.241/90, em nome do fato de que ela resultaria em enormes transtornos para a economia, com a injeção de trilhões, o que poderia trazer 0 retorno de uma hiperinflação9 .

Sobre a concentração de poderes nas mãos do Poder Executivo, veja-se a lição de Vera de Araújo Grilo:

[...] a longa vida da teoria da separação dos poderes tem demonstrado que essa concentração surge inúmeras vezes e, nos dias atuais, está sempre nas mãos do Executivo. Essa hegemonia do Executivo, se não estiver expressamente institucionalizada, acontecerá sempre que as circunstâncias

\footnotetext{
5 OLIVEIRA JUNIOR, José Alcebíades. Politização do Direito e Juridicização da Política. In Revista Sequência, no 32, p. 12.

6 VIANNA, Luiz Werneck e outros. A Judicialização da Política e das Relações Sociais no Brasil, p. 49.

${ }^{7}$ VIANNA, Luiz Werneck e outros. A Judicialização da Política e das Relações Sociais no Brasil, p. 51.

${ }^{8}$ OLIVEIRA JUNIOR, José Alcebíades. Politização do Direito e Juridicização da Política. In Revista Sequência, no 32, p. 13.

${ }^{9}$ OLIVEIRA JUNIOR, José Alcebíades. Politização do Direito e Juridicização da Política. In Revista Sequência, no 32, p. 13.
} 
SCHMIDT, Felipe. Ministério Público, Poder Judiciário e Representação Funcional e Argumentativa: Fundamentos de Legitimidade para a atuação institucional. Revista Eletrônica Direito e Política, Programa de Pós-Graduação Stricto Sensu em Ciência Jurídica da UNIVALI, Itajaí, v.13, n.2, $2^{\circ}$ quadrimestre de 2018. Disponível em: www.univali.br/direitoepolitica - ISSN 1980-7791

políticas o permitirem. Isto quer dizer que ela não se estabelece quando encontra resistências da sociedade como um todo, ou dos outros poderes, zelosos em cumprir o papel que Ihes cabe constitucionalmente ${ }^{10}$.

E conclui:

Essas reflexões ajudam a concluir que, se a separação dos poderes, como teoria e como prática, tem permanecido nas Constituições de vários Estados como aval da democracia e das liberdades individuais, nem sempre tem conseguido impedir que surja a concentração de poderes.

A hipertrofia do Executivo, especialmente na história política brasileira, tem provado isso. Assim, não cabe a conclusão de que basta haver, na Constituição, a inserção do princípio da separação dos poderes para que se caracterize a não concentração de poderes em nenhum dos três ramos do governo. $O$ contrário tem sido provado pelos fatos, especialmente no Brasil (vide as décadas de 60, 70, e mesmo os anos 80 , de consolidação da democracia, só para ilustrar com períodos mais próximos): a inclusão da separação dos poderes como dogma constitucional, não impede que haja uma hipertrofia do Executivo. Essa vinculação entre concentração de poderes e o Poder Executivo, parece revelar, pelo menos no que tange ao Brasil, de modo até bastante enfático, o quanto estão distantes sociedade e Estado ${ }^{11}$.

Com efeito, cada vez mais o Estado é visto pelos cidadãos como um mero conjunto de serviços públicos destinados a atendê-lo ${ }^{12}$, e não mais como o centro de irradiação das decisões políticas fundamentais da sociedade, de modo que acaba por ter frequentemente que justificar para a coletividade quais as razões de sua existência ${ }^{13}$.

10 GRILO, Vera de Araújo. Reflexões sobre a teoria da separação dos poderes e a hegemonia do Poder Executivo. In Revista Sequência, n. 24, pp. 30/31.

11 GRILO, Vera de Araújo. Reflexões sobre a teoria da separação dos poderes e a hegemonia do Poder Executivo. In Revista Sequência, n. 24, pp. 33/34.

12 ABREU, Pedro Manoel. Jurisdição e Processo, p. 46.

${ }^{13}$ ABREU, Pedro Manoel. Jurisdição e Processo, p. 47. 
SCHMIDT, Felipe. Ministério Público, Poder Judiciário e Representação Funcional e Argumentativa: Fundamentos de Legitimidade para a atuação institucional. Revista Eletrônica Direito e Política, Programa de Pós-Graduação Stricto Sensu em Ciência Jurídica da UNIVALI, Itajaí, v.13, n.2, $2^{\circ}$ quadrimestre de 2018. Disponível em: www.univali.br/direitoepolitica - ISSN 1980-7791

Consoante Lenio Luiz Streck e José Luis Bolzan de Morais, a democracia representativa não mais atende aos anseios coletivos em face dos seguintes motivos:

a) seja em razão do número crescente daqueles que conquistavam a inserção no jogo político (o que inviabilizou a tomada de decisão por todos os interessados através das assembleias de cidadãos, como versão renovada da caricatura de democracia direta da Grécia Antiga); b) seja em face das dificuldades técnicas trazidas pelo tipo e conteúdo dos temas postos em discussão (o que transformou a política, muitas vezes, em refém das referências tecnológicas, das estatísticas, das probabilidades e das valorações macro e microeconômicas, o que dificultou/inviabilizou a tarefa política como jogo dialético de pretensões); c) seja, ainda, pelo volume quantitativo de questões postas à solução (o que implicou uma atividade full time que exclui o cidadão do jogo político, uma vez que ocupado demais em prover o seu cotidiano, ao mesmo temo que exclui o político do debate social dos temas) ${ }^{14}$.

Assim, como concluem os dois autores, a representação política precisa ser repensada ${ }^{15}$, na esteira do que entende Pedro Manoel Abreu, para quem "a representação política, por evidente, não pode tudo e muito menos é capaz de transformar os grandes ideais em realidade"16. E complementa:

A democracia representativa, em todos os países em que vigora, ademais, tem necessidade de renovação, por se defrontar com problemas crescentes de desinteresse da população pela política, elevados índices de absenteísmo e, o que é mais grave, hostilidade dos eleitores em relação aos políticos profissionais, sobretudo pela corrupção crônica, que parece minar a classe política, principalmente nos países emergentes, colocando em profundo descrédito as instituições ${ }^{17}$.

\footnotetext{
14 STRECK, Lenio Luiz; BOLZAN DE MORAIS, José Luis. Ciência Política \& Teoria do Estado, p. 161 .

15 STRECK, Lenio Luiz; BOLZAN DE MORAIS, José Luis. Ciência Política \& Teoria do Estado, p. 162.
}

16 ABREU, Pedro Manoel. Processo e Democracia, p. 282.

17 ABREU, Pedro Manoel. Jurisdição e Processo, p. 40. 
SCHMIDT, Felipe. Ministério Público, Poder Judiciário e Representação Funcional e Argumentativa: Fundamentos de Legitimidade para a atuação institucional. Revista Eletrônica Direito e Política, Programa de Pós-Graduação Stricto Sensu em Ciência Jurídica da UNIVALI, Itajaí, v.13, n.2, $2^{\circ}$ quadrimestre de 2018. Disponível em: www.univali.br/direitoepolitica - ISSN 1980-7791

Nesse quadro, também não tem se mostrado exitosa a tomada por atores econômicos privados, sejam nacionais ou transnacionais, de decisões acerca de questões com implicações coletivas, como vem ocorrendo no panorama atual de globalização.

Na lição de Milton Santos, "a partir de agora a produção se dá à escala mundial, por intermédio de empresas mundiais, que competem entre si segundo uma concorrência extremamente feroz, como jamais existiu"18. Segundo ele, tem-se "uma verdadeira mundialização do produto, do dinheiro, do crédito, da dívida, do consumo, da informação", o que "é também um fato novo"19. Diante desse contexto, aduz:

Há um verdadeiro retrocesso quanto à noção de bem público e de solidariedade, do qual é emblemático o encolhimento das funções sociais e políticas do Estado com a ampliação da pobreza e os crescentes agravos à soberania, enquanto se amplia o papel político das empresas na regulação da vida social ${ }^{20}$.

Com efeito, no século XXI a demora para a tomada de decisões no âmbito do sistema democrático-representativo tradicional, decorrente da elevada complexidade inerente ao processo legislativo, cuja observância é impositiva, não se mostra compatível com a rapidez exigida pela circulação internacional do capital $^{21}$.

Assim, como a deliberação no processo político tradicional demanda tempo, que nem sempre está disponível ao capital transnacional, decisões que acabam por repercutir sobre toda a coletividade $(v . g$. alocação ou retirada de recursos de dado país) são tomadas por gestores de empresas privadas, à revelia do Estado

\footnotetext{
18 SANTOS, Milton. Por uma outra globalização, pp. 29/30.

${ }^{19}$ SANTOS, Milton. Por uma outra globalização, p. 30.

20 SANTOS, Milton. Por uma outra globalização, p. 38.

${ }^{21}$ Notas de aula da disciplina Teoria Jurídica e Transnacionalidade, ministrada pelo Professor Doutor Maurizio Oliviero, no segundo semestre do ano letivo de 2015 no Programa de PósGraduação Strictu Sensu em Ciência Jurídica da Universidade do Vale do Itajaí.
} 
SCHMIDT, Felipe. Ministério Público, Poder Judiciário e Representação Funcional e Argumentativa: Fundamentos de Legitimidade para a atuação institucional. Revista Eletrônica Direito e Política, Programa de Pós-Graduação Stricto Sensu em Ciência Jurídica da UNIVALI, Itajaí, v.13, n.2, $2^{\circ}$ quadrimestre de 2018. Disponível em: www.univali.br/direitoepolitica - ISSN 1980-7791

e mesmo de fora de suas fronteiras, produzindo profundas crises econômicas e financeiras e agravando a exclusão social em diversas partes do globo ${ }^{22}$.

À vista desse quadro de crise da democracia representativa e de inadequação dos agentes econômicos para gestão dos interesses políticos da coletividade, na lição de Pedro Manoel Abreu, "o Judiciário, seja como ator coletivo, seja por meio do trabalho do juiz individual, 'abandona o seu canto neutro e se identifica com a preservação dos valores universais em uma sociedade que cada vez menos se reconhece no seu Estado, em seus partidos e no seu sistema de representação'"'23.

Tal alteração do papel do Poder Judiciário em face da sociedade civil veio acompanhada de mudança análoga na atuação do Ministério Público, instituição que não é Poder do Estado ${ }^{4}$ (art. $2^{0}$ da Constituição da República), embora tenha garantias de Poder e desempenhe papel essencial para o funcionamento de um dos Poderes, e cujos membros há tempo deixaram de ser Procuradores do Rei $^{25}$ para se tornar, notadamente a partir da Constituição de 1988 , defensores da coletividade.

Aliás, em face do princípio da inércia que rege a jurisdição no Brasil (art. $2^{\circ}$ do CPC/2015), não se afigura despropositado afirmar que o Poder Judiciário apenas assumiu a posição de protagonismo social que hodiernamente ocupa por força, ao menos no que tange àquelas questões de contornos eminentemente coletivos, da atuação do próprio Ministério Público, que abandonou a condição de mero parecerista em matéria civil para assumir postura de órgão agente na promoção dos interesses transindividuais, tanto na via judicial (no que acabou por contribuir para o protagonismo do Poder Judiciário) quanto extrajudicial (em que,

\footnotetext{
22 Notas de aula da disciplina Teoria Jurídica e Transnacionalidade, ministrada pelo Professor Doutor Maurizio Oliviero, no segundo semestre do ano letivo de 2015 no Programa de PósGraduação Strictu Sensu em Ciência Jurídica da Universidade do Vale do Itajaí.

${ }^{23}$ ABREU, Pedro Manoel. Processo e Democracia, p. 271.

${ }^{24}$ MAZZILLI, Hugo Nigro. Ministério Público, pp. 37/38.

${ }^{25}$ MAZZILLI, Hugo Nigro. Ministério Público, p. 26.
} 
SCHMIDT, Felipe. Ministério Público, Poder Judiciário e Representação Funcional e Argumentativa: Fundamentos de Legitimidade para a atuação institucional. Revista Eletrônica Direito e Política, Programa de Pós-Graduação Stricto Sensu em Ciência Jurídica da UNIVALI, Itajaí, v.13, n.2, $2^{\circ}$ quadrimestre de 2018. Disponível em: www.univali.br/direitoepolitica - ISSN 1980-7791

sem prejuízo de sua atuação perante a jurisdição, vem construindo seu próprio protagonismo).

Todavia, como tanto o Poder Judiciário quanto o Ministério Público não têm seus integrantes periodicamente eleitos pelo voto popular nem sujeitos à possibilidade de censura por intermédio da não recondução, há que se investigar quais seriam os fundamentos de legitimidade de sua atuação perante a coletividade.

\section{A REPRESENTAÇÃO FUNCIONAL}

A propósito das consequências da crise do sistema democrático-representativo acima sucintamente delineado, aduz Luiz Werneck Vianna:

tal contexto institucional, dominante, em maior ou menor medida, nos países ocidentais, além de expressar um movimento de invasão do direito na política e na sociabilidade, tem dado origem a um novo personagem da intelligentzia: os magistrados e os membros do Ministério Público ${ }^{26}$.

Quanto aos magistrados, segundo Pedro Manoel Abreu,

[...] os agentes políticos (...) encontraram no Judiciário um novo interlocutor e uma nova arena, tanto para seus confrontos quanto para contestar políticas governamentais e decisões de maiorias legislativas. O cidadão, de outra parte, localizou na instituição um espaço para a solução de disputas e para a garantia dos mais variados direitos ${ }^{27}$.

No que toca ao Ministério Público, pelo menos desde a Constituição de 1988, pela qual foi refundado ${ }^{28}$, seja por Ihe ter conferido a condição de instituição permanente e essencial à função jurisdicional do Estado, seja por lhe ter atribuído o mister de defesa da ordem jurídica, do regime democrático e dos interesses sociais e individuais indisponíveis (art. 127, caput, da Constituição da

\footnotetext{
${ }^{26}$ VIANNA, Luiz Werneck e outros. A Judicialização da Política e das Relações Sociais no Brasil, p. 23.

${ }^{27}$ ABREU, Pedro Manoel. Jurisdição e Processo, pp. 52/53.

${ }^{28}$ ABREU, Pedro Manoel. Jurisdição e Processo, p. 52.
} 
SCHMIDT, Felipe. Ministério Público, Poder Judiciário e Representação Funcional e Argumentativa: Fundamentos de Legitimidade para a atuação institucional. Revista Eletrônica Direito e Política, Programa de Pós-Graduação Stricto Sensu em Ciência Jurídica da UNIVALI, Itajaí, v.13, n.2, $2^{\circ}$ quadrimestre de 2018. Disponível em: www.univali.br/direitoepolitica - ISSN 1980-7791

República), vem ele assumido protagonismo, tanto em matéria criminal, na qualidade de titular da ação penal e da atividade investigatória de graves crimes envolvendo empresários, políticos e servidores públicos de alto escalão, quanto em matéria civil, como principal titular da ação civil pública para tutela de interesses transindividuais, em que se discutem questões de relevo para toda a coletividade ( $v . g$. moralidade administrativa, meio ambiente, relações de consumo, ordem econômica, ordem urbanística, patrimônio cultural). Assim, em face da relevância social de sua atuação, o Ministério Público vem "obtendo, desse modo, uma divulgação significativa de suas ações nos espaços midiáticos" 29 .

Todavia, a despeito de virem conquistando crescente importância no contexto social atual, há que se reconhecer que tanto o Poder Judiciário quanto o Ministério Público não possuem legitimação democrática, à míngua da eleição periódica de seus membros pelo voto popular, legitimando-se, ao revés, por desempenharem uma representação funcional da sociedade, que decorre, como a própria expressão revela, da natureza das funções que exercem, emanadas da Constituição e das leis ${ }^{30}$.

A ideia de representação funcional no Brasil tem como marco inicial a Revolução de $1930^{31}$, que inaugura a chamada "Era Vargas", e pode ser vinculada tanto ao campo jurídico estatal, como ocorre no caso do Poder Judiciário e do Ministério Público, quanto à sociedade civil organizada, como se dá com os sindicatos e as ONGs.

A despeito de remontar aos anos 30 do século $X X$, a representação funcional

29 MOTTA, Luiz Eduardo. Judicialização da Política e Representação Funcional no Brasil Contemporâneo: uma ameaça à soberania popular? In Revista Quaestio Juris, vol. 05, no 01 , p. 260 .

30 ABREU, Pedro Manoel. Processo e Democracia, p. 291.

31 RUEDIGER, Marco Aurelio; RICCIO, Vicente; MOTTA, Luiz Eduardo Pereira da. A Representação Funcional como Instrumento de Efetivação de Direitos: uma Herança da era Vargas. Estudo apresentado no $30^{\circ}$ Encontro da ANPAD - Associação Nacional de PósGraduação e Pesquisa em Administração, em setembro de 2006. Disponível na internet: http://www.anpad.org.br/enanpad/2006/dwn/enanpad2006-apsa-2062.pdf; acesso em 18/1/2017. 
SCHMIDT, Felipe. Ministério Público, Poder Judiciário e Representação Funcional e Argumentativa: Fundamentos de Legitimidade para a atuação institucional. Revista Eletrônica Direito e Política, Programa de Pós-Graduação Stricto Sensu em Ciência Jurídica da UNIVALI, Itajaí, v.13, n.2, $2^{\circ}$ quadrimestre de 2018. Disponível em: www.univali.br/direitoepolitica - ISSN 1980-7791

ainda na atualidade vem se mantendo como canal para a resolução de conflitos sociais e a efetivação de direitos, tendo adquirido maior relevância com a redemocratização do Brasil a partir de 1988. Assim, embora seja autoritária em suas origens, por que atrelada ao corporativismo que regia as relações público/privado no Brasil à época de seu surgimento, a ideia de representação funcional acabou por assumir outros contornos ${ }^{32}$, expressando "uma nova tendência da democracia contemporânea"33.

Segundo Rudiger, Riccio e Motta,

[...] ao lado da representação política, a representação funcional tem sobrevivido ao longo do tempo, a despeito das mudanças no campo político brasileiro, a exemplo do período liberaldemocrático de 1945/1964, e do regime tecnocráticomilitar de 1964/1985. A Constituição de 1988, longe de ter findado a representação funcional, ampliou a sua presença, tendo em destaque as instituições jurídicas como o Ministério Público, sendo este definido como representante legal dos direitos coletivos e difusos da sociedade. Assim sendo, as instituições do direito tornaram-se um expressivo canal de representação entre a sociedade e o Estado, constituindo, dessa forma, um novo cenário da democracia brasileira ${ }^{34}$.

Assim, renovada pelo constituinte de 1988, a representação funcional da sociedade, própria do regime democrático, pois sua presença seria mais difícil num sistema autoritário, caracterizado pela concentração de poder no Executivo ${ }^{35}$, tornou-se "um componente essencial do processo político da

32 MELLO, Myrian de Fátima Correia de. Judicialização e Representatividade: a representação funcional na percepção dos representantes políticos da sociedade brasileira, p. 59.

33 MOTTA, Luiz Eduardo. Judicialização da Política e Representação Funcional no Brasil Contemporâneo: uma ameaça à soberania popular? In Revista Quaestio Juris, vol. 05, no 01 , p. 258 .

34 RUEDIGER, Marco Aurelio; RICCIO, Vicente; MOTTA, Luiz Eduardo Pereira da. A Representação Funcional como Instrumento de Efetivação de Direitos: uma Herança da era Vargas. Estudo apresentado no $30^{\circ}$ Encontro da ANPAD - Associação Nacional de PósGraduação e Pesquisa em Administração, em setembro de 2006. Disponível na internet: http://www.anpad.org.br/enanpad/2006/dwn/enanpad2006-apsa-2062.pdf; acesso em 18/1/2017.

35 MOTTA, Luiz Eduardo. Judicialização da Política e Representação Funcional no Brasil 
SCHMIDT, Felipe. Ministério Público, Poder Judiciário e Representação Funcional e Argumentativa: Fundamentos de Legitimidade para a atuação institucional. Revista Eletrônica Direito e Política, Programa de Pós-Graduação Stricto Sensu em Ciência Jurídica da UNIVALI, Itajaí, v.13, n.2, $2^{\circ}$ quadrimestre de 2018. Disponível em: www.univali.br/direitoepolitica - ISSN 1980-7791

democracia" ${ }^{36}$, que obviamente não exclui, mas complementa o papel da representação democrática.

É o que se colhe da lição de Pedro Manoel Abreu:

Em verdade, as duas formas de representação - a funcional e a política - atuariam em uma relação de complementaridade, de reforço recíproco. Essa relação de complementaridade, extraída da tradição republicana brasileira, estaria atuando de forma compensatória em relação ao deficit democrático, especialmente contra a intervenção legislativa do Executivo ${ }^{37}$.

Na mesma linha vai o entendimento de Luiz Werneck Vianna e Marcelo Burgos, que sustentam haver "uma parceria institucional entre as duas formas de representação, do que é exemplo a frequência com que os partidos políticos recorrem à iniciativa do Ministério Público"38.

Ademais, o próprio Poder Legislativo, por meio de seus parlamentares ou de suas Comissões, tem mobilizado o Ministério Público, trazendo-lhe notícia de fatos e solicitando a deflagração de inquéritos civis e outros procedimentos investigatórios para apurá-los, de modo que, ao fazê-lo, acaba por implicitamente admitir que não detém o monopólio da representação política ${ }^{39}$, e

Contemporâneo: uma ameaça à soberania popular? In Revista Quaestio Juris, vol. 05, no 01 , pp. $258 / 259$.

36 MELLO, Myrian de Fátima Correia de. Judicialização e Representatividade: a representação funcional na percepção dos representantes políticos da sociedade brasileira, p. 64.

${ }^{37}$ ABREU, Pedro Manoel. Processo e Democracia, pp. 288/289.

38 VIANNA, Luiz Werneck; BURGOS, Marcelo. Revolução Processual do Direito e Democracia Progressiva. In VIANNA, Luiz Werneck (Org.). A Democracia e os três poderes no Brasil, pp. 384/385, apud ABREU, Pedro Manoel. Processo e Democracia, p. 288 (nota 727).

39 MELLO, Myrian de Fátima Correia de. Judicialização e Representatividade: a representação funcional na percepção dos representantes políticos da sociedade brasileira, p. 70. 
SCHMIDT, Felipe. Ministério Público, Poder Judiciário e Representação Funcional e Argumentativa: Fundamentos de Legitimidade para a atuação institucional. Revista Eletrônica Direito e Política, Programa de Pós-Graduação Stricto Sensu em Ciência Jurídica da UNIVALI, Itajaí, v.13, n.2, $2^{\circ}$ quadrimestre de 2018. Disponível em: www.univali.br/direitoepolitica - ISSN 1980-7791

autoriza concluir que há outros modos de participar da vida pública ${ }^{40}$.

E cabe anotar que não só os partidos políticos e o Poder Legislativo procuram a iniciativa do Ministério Público, mas também outras entidades da sociedade civil (v.g. associações, empresas) e órgãos públicos (v.g. Vigilância Sanitária, PROCON, Conselho Tutelar, órgãos ambientais), mesmo que por vezes disponham da mesma legitimidade para a adoção de medidas judiciais (v.g. propositura de ações) ou extrajudiciais ( $v . g$. celebração de termos de ajustamento de conduta por alguns órgãos públicos) cabíveis, além dos próprios cidadãos individualmente considerados (que seriam legitimados ao ajuizamento da ação popular para a tutela de alguns interesses coletivos, v.g.), sendo certo que o atendimento ao público (atender a qualquer do povo e adotar as providências cabíveis) constitui relevante atribuição institucional do Ministério Público (art. 32, II, da Lei n. 8.625/93).

Ora, a procura desses diversos atores sociais pela atuação do Ministério Público vem reforçar a representação funcional exercida por este e revelar que ela em nada conflita com a democracia representativa, mas, ao contrário, a fortalece.

Portanto, a representação funcional evidentemente não pretende abolir a democracia e substituí-la por um sistema novo, mas "multiplicar os corpos representativos e complementá-los por formas de representação funcional de interesses sociais organizados, seja diretamente, pelas formas corporativas de interesse societal, seja indiretamente, pelas instituições de direito estatal"41.

Ainda quanto à representação funcional pelo Ministério Público, que ganhou maior reconhecimento em face da criação dos instrumentos de tutela dos interesses difusos e coletivos, colhe-se da lição de Luiz Werneck Vianna e

40 MELLO, Myrian de Fátima Correia de. Judicialização e Representatividade: a representação funcional na percepção dos representantes políticos da sociedade brasileira, p. 71 .

${ }^{41}$ MOTTA, Luiz Eduardo. Judicialização da Política e Representação Funcional no Brasil Contemporâneo: uma ameaça à soberania popular? In Revista Quaestio Juris, vol. 05, no 01, p. 266. 
SCHMIDT, Felipe. Ministério Público, Poder Judiciário e Representação Funcional e Argumentativa: Fundamentos de Legitimidade para a atuação institucional. Revista Eletrônica Direito e Política, Programa de Pós-Graduação Stricto Sensu em Ciência Jurídica da UNIVALI, Itajaí, v.13, n.2, $2^{\circ}$ quadrimestre de 2018. Disponível em: www.univali.br/direitoepolitica - ISSN 1980-7791

Marcelo Burgos:

A Constituição de 1988 , documento com que o país se reencontra com a democracia política, longe de erradicar as formas de representação funcional, não somente as consagra, como lhes concede um novo e afirmativo papel ao entendê-las, tacitamente, como parte integrante dos mecanismos da democracia participativa. Confiou-se, assim, ao Ministério Público - órgão não eleito de inequívoco caráter de representação funcional - a representação da ordem jurídica e dos interesses sociais e individuais indisponíveis, convertendo-o em uma instituição aberta aos interesses da sociedade ${ }^{42}$.

De fato, por intermédio do exercício de suas amplas funções institucionais (art. 127 e art. 129 da Constituição da República de 1988) e do emprego de seus variados instrumentos de atuação judicial e extrajudicial (v.g. ação civil pública, inquérito civil, recomendação, termo de ajustamento de condutas, audiência pública, poder requisitório), que Ihe foram conferidos a partir da década de 1980, notadamente da Constituição da República de 1988, o Ministério Público vem desempenhando relevante papel de interlocução entre o Estado e a sociedade civil por meio de sua representação funcional.

Aliás, a própria nova organização do Ministério Público, prevista pela Constituição da República de 1988, contribuiu decisivamente para que a instituição se desincumbisse de forma mais eficiente de suas funções e, por conseguinte, melhor exercesse sua representação funcional.

É que, embora nascido à sombra do Poder Executivo, de quem era verdadeiro apêndice na Primeira República (pelo disposto no Decreto n. 848/1890 cabia ao Procurador-Geral da República cumprir as ordens do Governo da República relativas ao exercício de suas funções), e tendo se desenvolvido atrelado ao Poder Judiciário (pela Constituição de 1891 o Ministério Público era disciplinado no capítulo do Poder Judiciário, e o Procurador-Geral da República era escolhido entre os Ministros do Supremo Tribunal Federal), com avanços em períodos

42 IANNA, Luiz Werneck; BURGOS, Marcelo. Revolução Processual do Direito e Democracia Progressiva. In VIANNA, Luiz Werneck (Org.). A Democracia e os três poderes no Brasil, pp. 384/385, apud ABREU, Pedro Manoel. Processo e Democracia, p. 288 (nota 727). 
SCHMIDT, Felipe. Ministério Público, Poder Judiciário e Representação Funcional e Argumentativa: Fundamentos de Legitimidade para a atuação institucional. Revista Eletrônica Direito e Política, Programa de Pós-Graduação Stricto Sensu em Ciência Jurídica da UNIVALI, Itajaí, v.13, n.2, $2^{\circ}$ quadrimestre de 2018. Disponível em: www.univali.br/direitoepolitica - ISSN 1980-7791

democráticos (Constituições de 1934, a primeira a lhe assegurar tratamento institucional, e de 1946, que lhe concedeu capítulo próprio e ampliou as garantias de seus membros) e retrocessos em períodos ditatoriais (Constituições de 1937, que praticamente ignorou a existência da instituição, e Emenda Constitucional n. 1 de 1969, que tornou a atrelá-la ao Poder Executivo), com a Constituição de 1988, de viés democrático, o Ministério Público experimentou notável evolução: se destacou dos três Poderes do Estado (art. $2^{\circ}$ da Constituição da República), teve reconhecidos como seus princípios institucionais a unidade, a indivisibilidade e a independência funcional (art. 127, $\S 1^{\circ}$, da Constituição da República), recebeu autonomia funcional, administrativa (art. 127, §20, da Constituição da República) e financeira (art. 127, §§ $3^{\circ}$ a $6^{\circ}$ da Constituição da República), foi organizado em estrutura que reflete a forma federativa de Estado, com previsão de Ministério Público da União e Ministérios Públicos dos Estados (art. 128 da Constituição da República), teve fixada a escolha de sua chefia entre integrantes da carreira e a destituição dela mediante prévia autorização do Poder Legislativo (art. 128, §§ $1^{\circ}$ a 40, da Constituição da República) e seus membros receberam as garantias de vitaliciedade, inamovibilidade e irredutibilidade de subsídios (ar. 128, §5º, I, da Constituição da República) e as vedações de receber honorários, percentagens ou custas processuais, exercer a advocacia, participar de sociedade comercial, exercer, ainda que em disponibilidade, qualquer outra função pública, salvo uma de magistério, desempenhar atividade político-partidária, e receber, a qualquer título ou pretexto, auxílios ou contribuições de pessoas físicas, entidades públicas ou privadas (art. 128, §50, II, da Constituição da República), além de Ihes ser vedado exercer a advocacia no juízo ou tribunal perante o qual oficiavam, antes de decorridos três anos do afastamento do cargo por aposentadoria ou exoneração (art. 128, §60, da Constituição da República), sendo certo que atualmente lhe é proibido exercer a representação judicial e a consultoria jurídica de entidades públicas (art. 129, IX, da Constituição da República).

Assim, dotando o Ministério Público de tal estrutura organizacional, princípios, autonomia, garantias e vedações, o poder constituinte originário claramente 
SCHMIDT, Felipe. Ministério Público, Poder Judiciário e Representação Funcional e Argumentativa: Fundamentos de Legitimidade para a atuação institucional. Revista Eletrônica Direito e Política, Programa de Pós-Graduação Stricto Sensu em Ciência Jurídica da UNIVALI, Itajaí, v.13, n.2, $2^{\circ}$ quadrimestre de 2018. Disponível em: www.univali.br/direitoepolitica - ISSN 1980-7791

"pretendeu valorizar a representação funcional"43 do órgão ministerial, que antes da Constituição de 1988 era mais voltado ao Estado que à sociedade, e depois dela assumiu posição inversa.

Sobre esse ponto, leciona Luiz Eduardo Motta:

Maria Tereza Sadek - pioneira, ao lado de Werneck Vianna, em pesquisas no campo das Ciências Sociais sobre a judicialização no Brasil - converge em muitos aspectos com essa posição no tocante ao fortalecimento da representação funcional do Ministério Público a partir de 1988, e o papel de destaque que vem obtendo no cenário político brasileiro. De fato, a sua atual estrutura organizacional, como a sua autonomia, não tinha precedente na história de nossa formação social, e tampouco um modelo similar internacional, pelo menos que anteceda a 1988. Tanto Sadek como Werneck Vianna ressaltam o novo papel que o MP tem exercido, já que deixou de ser advogado dos interesses do Estado para converte-se em defensor da sociedade (WERNECK VIANNA, 2008: p.101; SADEK, 2008: p.112). É o exemplo das ações do MP em relação à administração pública direta no que se refere ao controle das ações dos agentes públicos e das políticas públicas programadas pelo aparelho estatal, na qual recorrem à lei de responsabilidade fiscal e, desse modo, incorporando o controle da administração pública ao sistema de proteção dos interesses difusos e coletivos (WERNECK VIANNA 2008: p.104). Como afirma Sadek, a nova identidade e as novas atribuições designadas ao MP impuseram um novo perfil à instituição, tornando-a uma agência fundamental no controle de atos e ações de outros atores estatais, entidades governamentais e organizações sociais, bem como uma instituição defensora dos interesses e direitos constitucionais do cidadão e da sociedade (SADEK, 2008: p.115). Esse aspecto singular do MP no cenário político brasileiro em sua ação sobre as demais instituições públicas, o caracterizam enquanto um agente de accountability, concorrendo diretamente com outras representações funcionais estatais que têm como princípio normativo a avaliação e controle com base na lei de responsabilidade fiscal, notadamente os

43 MELLO, Myrian de Fátima Correia de. Judicialização e Representatividade: a representação funcional na percepção dos representantes políticos da sociedade brasileira, p. 67. 
SCHMIDT, Felipe. Ministério Público, Poder Judiciário e Representação Funcional e Argumentativa: Fundamentos de Legitimidade para a atuação institucional. Revista Eletrônica Direito e Política, Programa de Pós-Graduação Stricto Sensu em Ciência Jurídica da UNIVALI, Itajaí, v.13, n.2, $2^{\circ}$ quadrimestre de 2018. Disponível em: www.univali.br/direitoepolitica - ISSN 1980-7791

Tribunais de Contas ${ }^{44}$.

São esses elementos, em suma, que constituem a representação funcional do Ministério Público e legitimam sua atuação, ao lado do Poder Judiciário, como canal de participação da cidadania política organizada ${ }^{45}$.

Examinados alguns aspectos acerca da representação funcional pelo Ministério Público e Poder Judiciário, passa-se à apreciação da admissibilidade do exercício de uma representação argumentativa pelas duas instituições.

\section{A REPRESENTAÇÃO ARGUMENTATIVA}

Para além da representação funcional, cujos contornos foram acima sucintamente delineados, pode-se reconhecer a existência de uma representação argumentativa, conferida pela doutrina de Robert Alexy ao Tribunal Constitucional.

Representação argumentativa seria aquela que vincula representantes e representados não por meio de eleições, tal qual a representação democrática tradicional, mas pela adoção de argumentos racionais e objetivos que sejam aceitos como corretos por um número bastante de cidadãos.

Segundo Alexy, o Tribunal Constitucional, órgão detentor da representação argumentativa, responsável pelo exercício da jurisdição constitucional, não possui "regularmente uma legitimação democrática direta e o povo não tem, em regra, possibilidade de controle por denegação da reeleição"46, o que igualmente se dá, conforme visto, com os membros do Poder Judiciário e do Ministério Público.

\footnotetext{
44 MOTTA, Luiz Eduardo. Judicialização da Política e Representação Funcional no Brasil Contemporâneo: uma ameaça à soberania popular? In Revista Quaestio Juris, vol. 05, no 01 , pp. $267 / 268$.

45 MELLO, Myrian de Fátima Correia de. Judicialização e Representatividade: a representação funcional na percepção dos representantes políticos da sociedade brasileira, p. 72.

${ }^{46}$ ALEXY, Robert. Constitucionalismo Discursivo, p. 162.
} 
SCHMIDT, Felipe. Ministério Público, Poder Judiciário e Representação Funcional e Argumentativa: Fundamentos de Legitimidade para a atuação institucional. Revista Eletrônica Direito e Política, Programa de Pós-Graduação Stricto Sensu em Ciência Jurídica da UNIVALI, Itajaí, v.13, n.2, $2^{\circ}$ quadrimestre de 2018. Disponível em: www.univali.br/direitoepolitica - ISSN 1980-7791

Assim, Alexy indaga se a jurisdição constitucional seria compatível com a democracia, de modo que também pudesse ser compreendida como representação do povo, questionamento que pode ser projetado, em sua literalidade, para o Poder Judiciário e o Ministério Público.

Neste passo, cumpre esclarecer que a projeção de tal indagação, formulada por Robert Alexy quanto ao Tribunal Constitucional, para o Poder Judiciário e o Ministério Público, se afigura viável inicialmente porque nenhum desses três órgãos, como já afirmado, possui legitimidade democrática decorrente da eleição pelo voto popular nem está sujeito à possibilidade de denegação pela reeleição, no que se equiparam.

Outrossim, no Brasil a jurisdição constitucional, que seria, na percepção de Alexy, a detentora da representação argumentativa, é afeta não só ao Supremo Tribunal Federal e aos Tribunais de Justiça dos Estados, que fariam as vezes de Corte Constitucional em sede de controle concentrado de constitucionalidade, tal qual o Tribunal Constitucional de Alexy, mas a todo o Poder Judiciário (incluindo aqueles dois órgãos), que exerce, incidentalmente, o controle difuso de constitucionalidade.

Quanto ao Ministério Público, qualquer pessoa do povo, valendo-se do direito constitucional de petição aos poderes públicos, pode se dirigir ao ProcuradorGeral da República ou ao Procurador-Geral de Justiça representando acerca de alguma inconstitucionalidade em abstrato, para que se proponha, perante a Corte competente (Supremo Tribunal Federal ou Tribunal de Justiça do Estado, respectivamente) a ação de controle abstrato de constitucionalidade que se afigure cabível.

Ademais, a crise do sistema democrático-representativo e o consequente papel de protagonismo social que o Poder Judiciário e o Ministério Público vêm desempenhando no Brasil, conforme acima delineado, também autorizam a extensão das concepções afetas à representação argumentativa a esses dois órgãos.

Com efeito, o questionamento em tela, acerca da compatibilidade da jurisdição 
SCHMIDT, Felipe. Ministério Público, Poder Judiciário e Representação Funcional e Argumentativa: Fundamentos de Legitimidade para a atuação institucional. Revista Eletrônica Direito e Política, Programa de Pós-Graduação Stricto Sensu em Ciência Jurídica da UNIVALI, Itajaí, v.13, n.2, $2^{\circ}$ quadrimestre de 2018. Disponível em: www.univali.br/direitoepolitica - ISSN 1980-7791

constitucional com a democracia, não era extensível a tais órgãos ao tempo em que o Poder Judiciário exercia as funções de singelo pacificador de lides interindividuais e o Ministério Público funcionava como mero parecerista nesses mesmos conflitos, porque tal espécie de litígio não compreende interesses de amplo alcance social. Todavia, com a incursão das duas instituições por novos campos de atuação que antes Ihes eram infensos, aos quais foram levados pela própria sociedade civil, que passou a buscá-los por não mais ver seus interesses espelhados no sistema democrático-representativo, a indagação formulada por Robert Alexy Ihes é em tudo pertinente.

Contudo, como reconhece o próprio Alexy, a compreensão do Tribunal Constitucional (aplicável, segundo ora se propõe, ao Poder Judiciário e ao Ministério Público) como representação do povo esbarra em dois óbices, que ele assim descreve:

Representação do povo parece, primeiro, necessariamente estar unido com eleições e, caso, segundo, fosse possível, porém, representação sem eleições, porque deveria esse tipo de representação ter primazia diante de uma representação que se apoia em eleições ${ }^{47}$

Como resposta a esses óbices, Robert Alexy considera que uma concepção adequada de democracia precisa abarcar a ideia de argumento, o que caracteriza uma democracia deliberativa e acaba por instituir a possibilidade de uma representação argumentativa. Nas palavras do autor:

A chave para a solução desse problema e, com isso, do problema geral da jurisdição constitucional é o conceito da representação argumentativa. Representação é uma relação de duas variáveis entre um repraesentandum e um repraesentans. No caso da dação de leis parlamentar, a relação entre o repraesentandum - o povo - e o repraesentans - o parlamento - é determinada, essencialmente, por eleições. Agora, é possível esboçar uma imagem da democracia, que contém nada mais que um procedimento de decisão centrado nos conceitos de eleição e de regra da maioria. Isso seria um modelo puramente

${ }^{47}$ ALEXY, Robert. Constitucionalismo Discursivo, p. 163. 
SCHMIDT, Felipe. Ministério Público, Poder Judiciário e Representação Funcional e Argumentativa: Fundamentos de Legitimidade para a atuação institucional. Revista Eletrônica Direito e Política, Programa de Pós-Graduação Stricto Sensu em Ciência Jurídica da UNIVALI, Itajaí, v.13, n.2, $2^{\circ}$ quadrimestre de 2018. Disponível em: www.univali.br/direitoepolitica - ISSN 1980-7791

\begin{abstract}
decisionista de democracia. Um conceito adequado de democracia, contudo, não se deve apoiar somente no conceito de decisão. Ele precisa também abarcar o de argumento. O abarcamento da argumentação no conceito de democracia torna a democracia deliberativa. A democracia deliberativa é a tentativa de institucionalizar o discurso, tão amplamente quanto possível, como meio da tomada de decisão pública ${ }^{48}$.
\end{abstract}

Assim, a representação do povo por órgãos cujos integrantes por ele não foram eleitos, tal quais, além do Tribunal Constitucional (ao qual se refere Alexy), o Poder Judiciário e o Ministério Público (aos quais ora se pretende ampliar o alcance da concepção de Alexy), seria "puramente argumentativa", abarcando "o discurso como elemento ideal"49.

Ora, não se pode esquecer que o Poder Judiciário e o Ministério Público têm a obrigação constitucional e legal de fundamentar, respectivamente, todas as suas decisões e manifestações, na forma do disposto no art. 93, IX, da Constituição da República, quanto ao Poder Judiciário, e no art. 129, VIII, parte final, e §40, da Constituição da República, e art. 43, III, da Lei n. 8.625/93, quanto ao Ministério Público.

Dessa forma, é justamente por intermédio da adequada (racional, razoável, objetiva, inteligível ao cidadão comum) fundamentação de suas decisões e manifestações que o Poder Judiciário e o Ministério Público podem (e, aliás, devem, à vista dos preceitos constitucionais e legais referidos) expor seus argumentos e assim construir seu discurso.

Todavia, aponta Alexy, ainda referindo-se à jurisdição constitucional, algum crítico poderia objetar que a representação puramente argumentativa é uma quimera, em que "não existem nem limites nem controle" 50, e que o constitucionalismo discursivo "termina em um lugar da ilusão, no qual tudo pode

ALEXY, Robert. Constitucionalismo Discursivo, p. 163.

49

ALEXY, Robert. Constitucionalismo Discursivo, p. 164.

50

ALEXY, Robert. Constitucionalismo Discursivo, p. 164. 
SCHMIDT, Felipe. Ministério Público, Poder Judiciário e Representação Funcional e Argumentativa: Fundamentos de Legitimidade para a atuação institucional. Revista Eletrônica Direito e Política, Programa de Pós-Graduação Stricto Sensu em Ciência Jurídica da UNIVALI, Itajaí, v.13, n.2, $2^{\circ}$ quadrimestre de 2018. Disponível em: www.univali.br/direitoepolitica - ISSN 1980-7791

ser legitimado. ${ }^{51 "}$

Alexy rejeita tal objeção aduzindo, em suma, que o argumento e o discurso não admitem tudo e podem "ser distinguidos argumentos jurídico-constitucionais bons de ruins ou melhores de piores" e ser compatibilizados com o que o povo pensa 52 . Assim, segundo Alexy, "fundamentação racional e, com isso, objetividade é possível na argumentação jurídico-constitucional, e precisamente, em uma medida considerável"53.

Também quanto ao Poder Judiciário e ao Ministério Público essa inteligência é em tudo aplicável, pois a própria obrigação constitucional e legal de fundamentar todas as decisões judiciais e manifestações ministeriais surge como óbice à aventada ausência de controle, destinando-se, ao revés, justamente a viabilizá-lo.

Acerca desse ponto, doutrina Rui Portanova:

Não se pode esquecer também que o Poder Judiciário emana do povo. Assim, a sentença é o momento em que o juiz mais responde ante o povo pelo uso que faz desse poder. Por isso, é imprescindível que a sentença seja clara e convincente para que o sentimento do juiz seja compreendido sem dificuldade ${ }^{54}$.

E prossegue:

A motivação permite o controle crítico da sentença (...). Não se pense que o destinatário da motivação é somente a parte. Trata-se de uma garantia para o Estado, os cidadãos, o próprio juiz e a opinião pública em geral ${ }^{55}$.

Mas a representação argumentativa autêntica ainda tem outros requisitos, assim

\footnotetext{
${ }^{51}$ ALEXY, Robert. Constitucionalismo Discursivo, p. 164.

52 ALEXY, Robert. Constitucionalismo Discursivo, p. 164.

${ }^{53}$ ALEXY, Robert. Constitucionalismo Discursivo, p. 165.

54 PORTANOVA, Rui. Princípios do Processo Civil, p. 249.

55 PORTANOVA, Rui. Princípios do Processo Civil, p. 250.
} 
SCHMIDT, Felipe. Ministério Público, Poder Judiciário e Representação Funcional e Argumentativa: Fundamentos de Legitimidade para a atuação institucional. Revista Eletrônica Direito e Política, Programa de Pós-Graduação Stricto Sensu em Ciência Jurídica da UNIVALI, Itajaí, v.13, n.2, $2^{\circ}$ quadrimestre de 2018. Disponível em: www.univali.br/direitoepolitica - ISSN 1980-7791

descritos por Alexy, também em tudo aplicáveis, pelas mesmas razões acima expostas, às decisões judiciais e manifestações ministeriais:

[...] é necessário que o tribunal não só promova a pretensão de que seus argumentos são os argumentos do povo ou do cidadão; um número suficiente de cidadãos precisa, pelo menos, em perspectiva mais prolongada, aceitar esses argumentos como corretos. Somente pessoas racionais estão capacitadas para aceitar um argumento por causa de sua correção ou validade. Isso mostra que existem duas condições fundamentais de representação argumentativa autêntica: (1) a existência de argumentos válidos ou corretos e (2) a existência de pessoas racionais que são capazes e dispostas a aceitar argumentos válidos ou corretos porque eles são válidos ou corretos. (...) Jurisdição constitucional somente então pode ser exitosa quando esses argumentos, que são alegados pelo tribunal constitucional, são válidos e quando membros, suficientemente muitos, da comunidade são capazes e dispostos de fazer uso de suas possibilidades racionais ${ }^{56}$.

E conclui:

Se essas condições estão cumpridas, a resposta à questão acima formulada, por que uma representação puramente argumentativa deve ter primazia diante de uma representação apoiada em eleições e reeleições, não mais é difícil. O constitucionalismo discursivo, como um todo, é a tentativa da institucionalização de razão e correção. Se existem argumentos válidos ou corretos, do mesmo modo como pessoas racionais, então razão e correção serão institucionalizadas melhor com jurisdição constitucional que sem ela ${ }^{57}$.

Por fim, há que se referir de modo expresso que a representação argumentativa se apresenta como complemento da representação funcional, e assim reciprocamente, até porque o adequado exercício da função, seja jurisdicional ou ministerial, exige fundamentação razoável, na forma acima exposta, e que a proposta constante deste estudo, acerca da legitimidade de uma representação não fundada sobre o voto popular, seja ela funcional e/ou argumentativa, não

\footnotetext{
${ }^{56}$ ALEXY, Robert. Constitucionalismo Discursivo, p. 165.

${ }^{57}$ ALEXY, Robert. Constitucionalismo Discursivo, p. 165.
} 
SCHMIDT, Felipe. Ministério Público, Poder Judiciário e Representação Funcional e Argumentativa: Fundamentos de Legitimidade para a atuação institucional. Revista Eletrônica Direito e Política, Programa de Pós-Graduação Stricto Sensu em Ciência Jurídica da UNIVALI, Itajaí, v.13, n.2, $2^{\circ}$ quadrimestre de 2018. Disponível em: www.univali.br/direitoepolitica - ISSN 1980-7791

pretende substituir ou superar a representação tradicional dos agentes políticos eleitos pelo povo, mas apenas criar, manter e se possível ampliar os canais de exercício da cidadania.

\section{CONSIDERAÇÕES FINAIS}

Assim, ao fim desse estudo, tem-se, em síntese, que:

a) o exercício de poder estatal pelo parlamento e o executivo é legítimo porque ambos representam o povo, sendo eleitos por eleição livre e igual e controlados por meio da sanção da não reeleição;

b) a representação política, à qual caberia a tomada das decisões sobre interesses gerais da coletividade, está em crise, ante a incompatibilidade entre a vontade popular e a vontade expressa pelas maiorias parlamentares e a concentração de poderes em excesso no Poder Executivo;

c) não tem se mostrado exitosa as tomadas, por atores econômicos privados, sejam nacionais ou transnacionais, de decisões acerca de questões com implicações coletivas, como vem ocorrendo no panorama atual de globalização, ante a produção de exclusão social e crises econômicas;

d) surgem como alternativa a esses problemas a busca pelo Poder Judiciário e Ministério Público, que sofreram mudança de perfil a partir da Constituição de 1988 e passaram a ter atuação mais proativa e voltada aos interesses coletivos;

e) ocorre que tanto o Poder Judiciário quanto o Ministério Público não têm seus integrantes periodicamente eleitos pelo voto popular nem sujeitos à possibilidade de censura por intermédio da não recondução, não se constituindo em órgãos de representação política;

f) o Ministério Público e o Poder Judiciário têm representação funcional, decorrente da natureza das funções que exercem, emanadas da Constituição e das leis, mas com viés democrático e não corporativo, que é reforçado pela busca de diversos atores sociais por sua atuação, notadamente para a tutela de interesse difusos e coletivos e questões de natureza social; 
SCHMIDT, Felipe. Ministério Público, Poder Judiciário e Representação Funcional e Argumentativa: Fundamentos de Legitimidade para a atuação institucional. Revista Eletrônica Direito e Política, Programa de Pós-Graduação Stricto Sensu em Ciência Jurídica da UNIVALI, Itajaí, v.13, n.2, $2^{\circ}$ quadrimestre de 2018. Disponível em: www.univali.br/direitoepolitica - ISSN 1980-7791

g) o Ministério Público e o Poder Judiciário têm também representação argumentativa, conferida originalmente apenas ao Tribunal Constitucional, que vincula representantes e representados não por meio de eleições, tal qual a representação democrática tradicional, mas pela adoção de argumentos racionais e objetivos que sejam aceitos como corretos por um número bastante de cidadãos;

h) a aplicação da representação argumentativa ao Ministério Público e ao Poder Judiciário dá-se porque ambos, tal qual o Tribunal Constitucional, não têm legitimação democrática direta advinda do povo por meio de eleições periódicas e têm a obrigação constitucional e legal de fundamentar suas decisões e manifestações, de forma adequada (racional, razoável, objetiva, inteligível ao cidadão comum), podendo assim expor seus argumentos e construir seu discurso;

i) a representação argumentativa se apresenta como complemento da representação funcional, e assim reciprocamente, e ambas não pretendem substituir ou superar a representação tradicional dos agentes políticos eleitos pelo povo, mas apenas criar, manter e se possível ampliar os canais de exercício da cidadania.

\section{REFERÊNCIA DAS FONTES CITADAS}

ABREU, Pedro Manoel. Jurisdição e Processo: desafios políticos do sistema de justiça na cena contemporânea. Florianópolis: Conceito, 2016.

ABREU, Pedro Manoel. Processo e Democracia. O processo jurisdicional como locus da democracia participativa e da cidadania inclusiva no Estado Democrático de Direito. Florianópolis: Conceito, 2011.

ALEXY, Robert. Constitucionalismo Discursivo. $4^{a}$ ed. Tradução de Luís Afonso Heck. Porto Alegre: Livraria do Advogado, 2015.

BRASIL. Constituição da República Federativa do Brasil. Promulgada em 5 de outubro de 1988. In Códigos Civil, Comercial, Processo Civil, Constituição Federal e legislação complementar. 7a ed. São Paulo: Saraiva, 2011.

GRILLO, Vera de Araújo. Reflexões sobre a Teoria da Separação dos Poderes e a Hegemonia do Poder Executivo. In Revista Sequência, no 24. Florianópolis, 1992; pp. 25-35. 
SCHMIDT, Felipe. Ministério Público, Poder Judiciário e Representação Funcional e Argumentativa: Fundamentos de Legitimidade para a atuação institucional. Revista Eletrônica Direito e Política, Programa de Pós-Graduação Stricto Sensu em Ciência Jurídica da UNIVALI, Itajaí, v.13, n.2, $2^{\circ}$ quadrimestre de 2018. Disponível em: www.univali.br/direitoepolitica - ISSN 1980-7791

MAZZILLI, Hugo Nigro. Ministério Público. 4a ed. São Paulo: Malheiros, 2015.

MELLO, Myrian de Fátima Correia de. Judicialização e Representatividade: a representação funcional na percepção dos representantes políticos da sociedade brasileira. Dissertação de Mestrado em Ciência Política. Rio de Janeiro: IUPERJ, 2009.

MORAES, Alexandre de. Jurisdição Constitucional e Tribunais Constitucionais. Garantia Suprema da Constituição. São Paulo: Atlas, 2000.

MOTTA, Luiz Eduardo. Judicialização da Política e Representação Funcional no Brasil Contemporâneo: uma ameaça à soberania popular? In Revista Quaestio Juris, vol. 05, no 0, Rio de Janeiro, 2012; pp. 256-285.

OLIVEIRA JUNIOR, José Alcebíades de. Politização do Direito e Juridicização da Política. In Revista Sequência, n. 32. Florianópolis, 1996; pp. 9-14.

PORTANOVA, Rui. Princípios do Processo Civil. $4^{a}$ ed. Porto Alegre: Livraria do Advogado, 2001.

RUEDIGER, Marco Aurelio; RICCIO, Vicente; MOTTA, Luiz Eduardo Pereira da. A Representação Funcional como Instrumento de Efetivação de Direitos: uma Herança da era Vargas. Estudo apresentado no $30^{\circ}$ Encontro da ANPAD Associação Nacional de Pós-Graduação e Pesquisa em Administração, em setembro de 2006. Disponível na internet: http://www.anpad.org.br/enanpad/2006/dwn/enanpad2006-apsa-2062.pdf; acesso em 18/1/2017.

SANTOS, Milton. Por uma outra Globalização. Do pensamento único à consciência universal. Rio de Janeiro: Record, 2001.

STRECK, Lenio Luiz; MORAIS, José Luís Bolzan de. Ciência Política \& Teoria do Estado. $8^{a}$ ed. Porto Alegre: Livraria do Advogado, 2014.

VIANNA, Luiz Werneck e outros. A Judicialização da Política e das Relações Sociais no Brasil. $2^{a}$ ed. Rio de Janeiro: Revan, 2014.

Recebido em: 25/04/2018

Aprovado em: 27/06/2018 